\title{
DESIGN, CHARACTERIZATION AND STATISTICAL OPTIMIZATION OF RAMOSETRON HYDROCHLORIDE MOUTH DISSOLVING FILM USING DESIGN OF EXPERIMENT
}

\section{SUWARNA SURESH BOBDE ${ }^{1,2}$, HEMRAJ M. TANK ${ }^{3}$}

1Department of Pharmaceutics, P. E. S's Rajaram and Tarabai Bandekar College of Pharmacy, Ponda, Goa, ${ }^{2}$ Department of Pharmaceutics, School of Pharmacy, RK University Rajkot, Gujarat, ${ }^{3}$ Department of Pharmaceutics, Atmiya Institute of Pharmacy. Rajkot, Gujarat Email: suwarnabobde@gmail.com

Received: 23 Nov 2018, Revised and Accepted: 12 Feb 2019

\section{ABSTRACT}

Objective: The present study aims to prepare a mouth dissolving film of ramosetron hydrochloride to provide relief to cancer patients suffering from nausea and vomiting.

Methods: Mouth dissolving film of ramosetron hydrochloride were prepared and optimized using three levels two factor design. The films were prepared using the solvent casting technique. The effect of formulation variables such as the concentration of HPMC E15, and honey on disintegration time, tensile strength and drug release from the film were studied. The films were evaluated for weight, thickness, folding endurance, tensile strength, percent elongation, surface $\mathrm{pH}$, disintegration time and drug release.

Results: All the films were found to be transparent, non-sticky and easily peelable. The concentration of HPMC E 15 and Honey was found to have a significant effect on disintegration time and drug release of the mouth dissolving film. Formulation R1 was found to the best formulation with $104.21 \%$ release in 9 min and disintegration time of 57 seconds.

Conclusion: It can be concluded that the developed mouth dissolving film could serve as an effective, convenient alternative to prevent nausea and vomiting in cancer patients of any age group.

Keywords: Ramosetron, Mouth dissolving, Film, Nausea, Vomiting, Antiemetic, 5HT 3 antagonist

(c) 2019 The Authors. Published by Innovare Academic Sciences Pvt Ltd. This is an open access article under the CC BY license (http://creativecommons.org/licenses/by/4.0/) DOI: http://dx.doi.org/10.22159/ijap.2019v11i2.30952

\section{INTRODUCTION}

Nausea and vomiting are very common symptoms in cancer patients on chemo or radiation therapy $[1,2]$. About $70-80 \%$ patient on treatment suffer from nausea and vomiting of varying severity [3]. This deteriorates the quality of life of cancer patients [1]. There are various national and international guidelines developed to prevent nausea and vomiting in cancer patients [4]. Advent of 5HT3 Antagonist has significantly improved control over nausea and vomiting in cancer patients [5].

Ramosetron hydrochloride is a tetrahydro benzimidazole derivative. It is a potent and selective 5HT3 receptor antagonist. It has the high binding affinity and dissociates slowly from the target receptors due to which it has long-lasting effects than the older agents [5]. Ramosetron hydrochloride is administered as $0.1 \mathrm{mg}$ oral tablet for prevention of nausea and vomiting in cancer patients. Cancer is a disease that can occur in any age group from children, adults to geriatric patients. Conventional dosage forms like tablets and capsules have to be swallowed with the help of water and hence is a disadvantage for patients who have difficulty in swallowing. Mouth dissolving films is an advanced oral dosage form that disintegrates and dissolves in the mouth without uptake of water and eliminates the need of swallowing the dosage form. It caters to patients who have difficulty in swallowing, unlike conventional dosage forms. The present research work aims in preparing a mouth dissolving film of ramosetron hydrochloride that would prevent nausea and vomiting and offer ease of administration to cancer patients of any age group and also to cancer patients suffering from dysphagia.

\section{MATERIALS AND METHODS}

Ramosetron Hydrochloride was obtained as a gift sample from Cadila Healthcare Ltd, Kundaim Goa. HPMC E15 was provided as a gift sample from Colorcon Asia pvt Ltd, Verna Goa. Dabur Honey was purchased from the local market. Sodium alginate, carageenan were provided as gift sample by Snap Alginate Ltd Mumbai. Ethanol and propylene glycol was purchased from S. D fine chemicals limited. Citric acid and methylparaben were procured from Molychem
Mumbai. Ascorbic acid was purchased from Avra synthesis Pvt Ltd, Aspartame was purchased from Ozone Chemicals Mumbai. PEG 400 was purchased from Hi-Media Pvt ltd. Distilled water prepared using in house plant was used for the research work.

\section{Preliminary trials}

Various film-forming polymers such as hydroxypropyl methylcellulose (HPMC) E15, sodium alginate, carageenan were screened for film forming capacity of which HPMC E15 was found be the best polymer forming the transparent and stiff film, and hence was selected. Honey was screened for its film modifying property when used in combination with HPMC E15. The drug ramosetron hydrochloride has good solubility in cosolvent ethanol and hence was used and studied for its effects on film formation.

\section{Experimental design/preparation of mouth dissolving films}

An experimental design consisting of nine formulations was set up, using two factors at three levels to statistically optimize mouth dissolving film of ramosetron hydrochloride. Solvent casting technique was used in the preparation of films. The independent variables used included two numeric factors X1-Concentration of HPMC E15, X2-Concentration of honey. The responses used for statistical optimization included Y1-Disintegration Time in seconds, Y2-Tensile strength of films in $\mathrm{Kg} / \mathrm{cm} 2$ and Y3-Drug Release at 9 min. The composition of the films prepared is given in table 1.

HPMC E15, used as the film-forming agent was soaked in the ethanol-water mixture overnight. The polymer solution was stirred on a magnetic stirrer until homogenous. Honey used as film modifier was added to the polymer solution followed by PEG 400 used as the plasticizer and stirred till homogenous. Citric acid, used as saliva stimulating agent, ascorbic acid as antioxidant and flavoring agent aspartame as sweetening agent and drug was dissolved in the remaining amount of water and added to the polymer solution. This was followed by addition of methylparaben used as the preservative, which was previously dissolved in propylene glycol. The prepared formulation was casted on glass petriplate and dried at room temperature. The dried films were carefully peeled and cut in $2 \mathrm{~cm} \mathrm{x}$ 
$2 \mathrm{~cm}$ films wrapped in aluminum foil and stored in desiccators. The prepared films were evaluated for weight, thickness, surface $\mathrm{pH}$, folding endurance, disintegration time, tensile strength, percent elongation, drug release, assay, and stability.

Table 1: Composition of ramosetron hydrochloride mouth dissolving formulation

\begin{tabular}{|c|c|c|c|c|c|c|c|c|c|}
\hline Ingredients & $\mathbf{R 1}$ & $\mathbf{R 2}$ & R3 & R4 & $\mathbf{R 5}$ & R6 & R7 & $\mathbf{R 8}$ & R9 \\
\hline Ramosetron HCL (mg) & 1.58 & 1.58 & 1.58 & 1.58 & 1.58 & 1.58 & 1.58 & 1.58 & 1.58 \\
\hline HPMC E15 (\%) & 3.5 & 3.75 & 4 & 3.5 & 3.75 & 4 & 3.5 & 3.75 & 4 \\
\hline Honey (\%) & 2 & 2 & 2 & 3 & 3 & 3 & 4 & 4 & 4 \\
\hline PEG $400(\%)$ & 1 & 1 & 1 & 1 & 1 & 1 & 1 & 1 & 1 \\
\hline Methyl Paraben (\%) & 0.01 & 0.01 & 0.01 & 0.01 & 0.01 & 0.01 & 0.01 & 0.01 & 0.01 \\
\hline Citric acid(\%) & 1 & 1 & 1 & 1 & 1 & 1 & 1 & 1 & 1 \\
\hline Ascorbic acid (\%) & 0.5 & 0.5 & 0.5 & 0.5 & 0.5 & 0.5 & 0.5 & 0.5 & 0.5 \\
\hline Aspartame(\%) & 0.5 & 0.5 & 0.5 & 0.5 & 0.5 & 0.5 & 0.5 & 0.5 & 0.5 \\
\hline Propylene glycol(\%) & 1 & 1 & 1 & 1 & 1 & 1 & 1 & 1 & 1 \\
\hline Ethanol (ml) & 5 & 5 & 5 & 5 & 5 & 5 & 5 & 5 & 5 \\
\hline Water qs (ml) & 10 & 10 & 10 & 10 & 10 & 10 & 10 & 10 & 10 \\
\hline
\end{tabular}

\section{Drug-excipient compatibility}

The formulation in the dry state was tested for drug excipient compatibility. The study was carried out using differential scanning calorimetry (Universal V4SA TA). The thermograms of drug alone and drug with polymer were recorded at a scanning rate of $1^{\circ} \mathrm{C}$ per minute in temperature range of $-100{ }^{\circ} \mathrm{C}$ to $400{ }^{\circ} \mathrm{C}$ in a nitrogen atmosphere. The recorded thermograms were checked for any unusual change in appearance or shift in the peaks.

\section{Evaluation of mouth dissolving film}

\section{Physical appearance}

The films obtained were checked visually for uniformity, clarity and tackiness.

\section{Microscopy}

The morphology and topography of the prepared films was observed by placing a $2 \mathrm{~cm} \times 2 \mathrm{~cm}$ cut film under the scanning electron microscope

\section{Weight}

The prepared and cut films of $2 \mathrm{~cm} \times 2 \mathrm{~cm}$ were weighed on sartorius electronic balance. An average and standard deviation of the reading of three films were recorded.

\section{Thickness}

The thickness of the film was measured at three places per film using micrometer (Mitutoyo, Japan). Average of the readings of three films were recorded.

\section{Folding endurance}

The films were individually folded in a plane manually till it produced visible crack and number of times it was folded to produce visible crack was noted as the folding endurance. An average of three films was recorded $[6,7]$.

\section{Tensile strength}

Tensile strength is the maximum stress applied on the film till it breaks. Tensile strength was calculated using the formula given below [8]:

$$
\text { Tensile strength }=\frac{\text { Load at failure }}{\text { film thickness } \times \text { film width }} \times 100
$$

An average and standard deviation of three readings of films were recorded.

\section{Disintegration time}

Disintegration test apparatus IP was used to measure the disintegration time of the films. Average of the readings of three films were recorded and standard deviation found.

\section{Drug release}

The drug release was determined using a modified dissolution apparatus as used by Dinge et al. $20 \mathrm{ml}$ of phosphate buffer $\mathrm{pH} 6.8$ was used as dissolution medium. The films were placed in $50 \mathrm{ml}$ beaker containing $20 \mathrm{ml}$ of dissolution medium and suspended in Dissolution apparatus-IP and run at speed of $50 \mathrm{rpm}$. The sample was drawn at 3, 6, 9,12,15,18, 21 min and content was measured spectrophotometrically at $248 \mathrm{~nm}$ using UV1800 (Shimadzu, Japan) [9].

\section{Statistical optimization using the design of experiments}

Design expert trial version 11.0 software of Stat ease Inc was used for optimization of ramosetron hydrochloride mouth dissolving films. Two way ANOVA at the significance level of $* \mathrm{P}<0.05$ and response surface graphs were used to find the contribution of each independent variable on the response.

\section{Stability study}

The best formulation was tested for stability at room temperature and ambient humidity for $90 \mathrm{~d}$ [6].

\section{RESULTS AND DISCUSSION}

\section{Preliminary trials}

The drug ramosetron hydrochloride is water soluble hence filmforming polymers that would form transparent films would be ideal. Hence placebo films were prepared using polymers, such as HPMC E15, sodium alginate and carrageenan. HPMC E15 was found to produce good results with non-tacky, transparent film. Among the plasticizers' used PEG 400, Propylene glycol and honey were screened. Honey, when used alone, produced stiff and crisp films that were difficult to peel while PEG 400 and propylene glycol produced easily peelable films but they lacked stiffness. Hence honey in combination with PEG 400 was used wherein honey would provide the necessary stiffness while PEG 400 would allow ease of removal of the film. Since the formulation incorporated honey, methylparaben was used as the preservative in the formulation.

\section{Experimental design}

The preliminary trials for the formulation of mouth dissolving film helped to select the factors for the study and the concentration to be used. The layout of the factorial design and the responses is as given in table 2 .

\section{Drug-excipient compatibility}

On comparison of the thermogram of pure drug Ramosetron Hydrochloride fig. 1 and drug with excipients fig. 2, it was observed that the endothermic peak of the pure drug was found to be at $228.66{ }^{\circ} \mathrm{C}$ while in presence of excipients it was found to be at $231.65^{\circ} \mathrm{C}$. The slight shift may be due to the presence of polymers. Since there were no major changes in thermogram it ruled out any possibility of incompatibility. 
Table 2: Layout of factorial design

\begin{tabular}{|c|c|c|c|c|c|c|c|}
\hline \multirow[t]{2}{*}{ Code } & \multicolumn{2}{|c|}{ Coded values } & \multicolumn{2}{|c|}{ Actual values in percentage (\%) } & \multicolumn{2}{|c|}{ Dependent variables } & \multirow[b]{2}{*}{ Y3 } \\
\hline & X1 & $\mathrm{X} 2$ & $\mathrm{X1}$ & $\mathrm{X} 2$ & Y1 & Y2 & \\
\hline R1 & -1 & -1 & 3.5 & 2 & 59.00 & 75.65 & 107.32 \\
\hline $\mathrm{R} 2$ & 0 & -1 & 3.75 & 2 & 66.66 & 82.47 & 104.49 \\
\hline R3 & +1 & -1 & 4 & 2 & 73.00 & 91.09 & 90.34 \\
\hline $\mathrm{R} 4$ & -1 & 0 & 3.5 & 3 & 70.00 & 85.68 & 89.07 \\
\hline R5 & 0 & 0 & 3.75 & 3 & 77.00 & 94.33 & 79.02 \\
\hline R6 & +1 & 0 & 4 & 3 & 89.00 & 100.84 & 74.89 \\
\hline R7 & -1 & +1 & 3.5 & 4 & 90.00 & 95.68 & 84.73 \\
\hline R8 & 0 & +1 & 3.75 & 4 & 94.66 & 104.67 & 79.77 \\
\hline R9 & +1 & +1 & 4 & 4 & 110.98 & 113.07 & 62.52 \\
\hline
\end{tabular}

$\mathrm{X} 1$ is \% of HPMC E15 X2 is \% of Honey Y1 is Disintegration Time in seconds Y2 is Tensile strength in $\mathrm{Kg} / \mathrm{cm} 2 \mathrm{Y} 3$ is drug release at 9 min of DS and $\mathrm{PH}$ respectively.

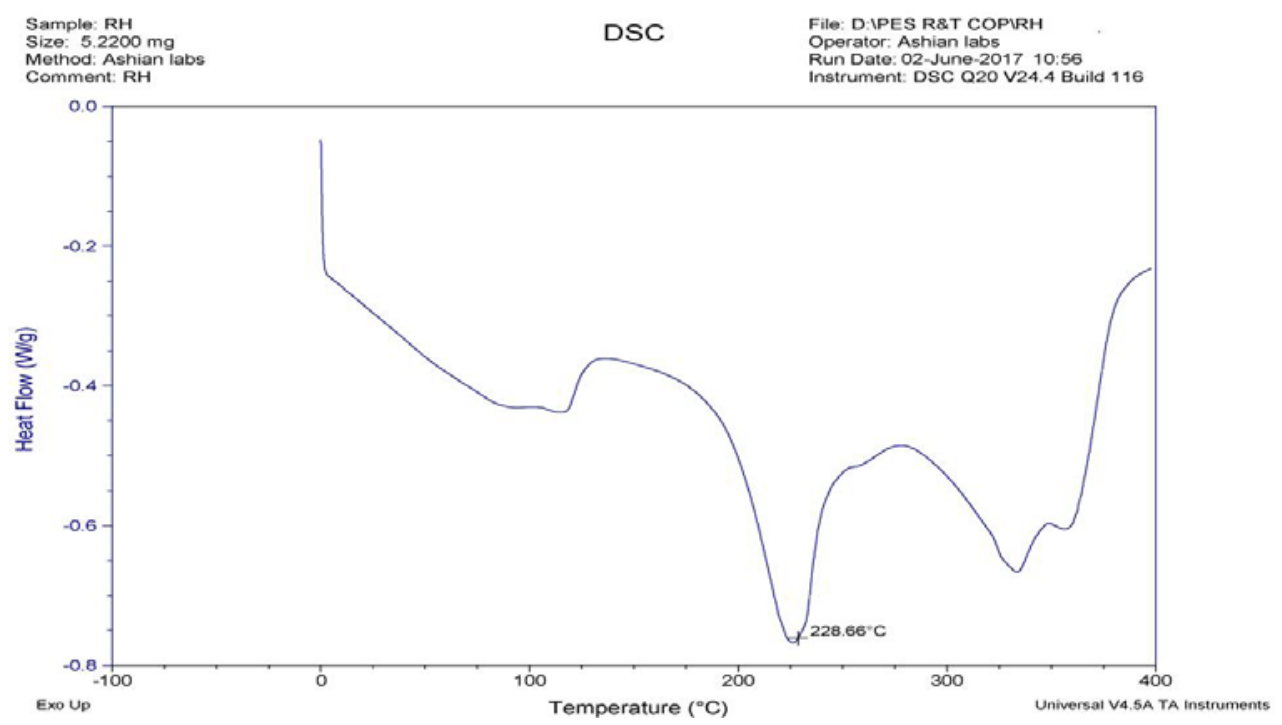

Fig. 1: DSC spectra of ramosetron hydrochloride

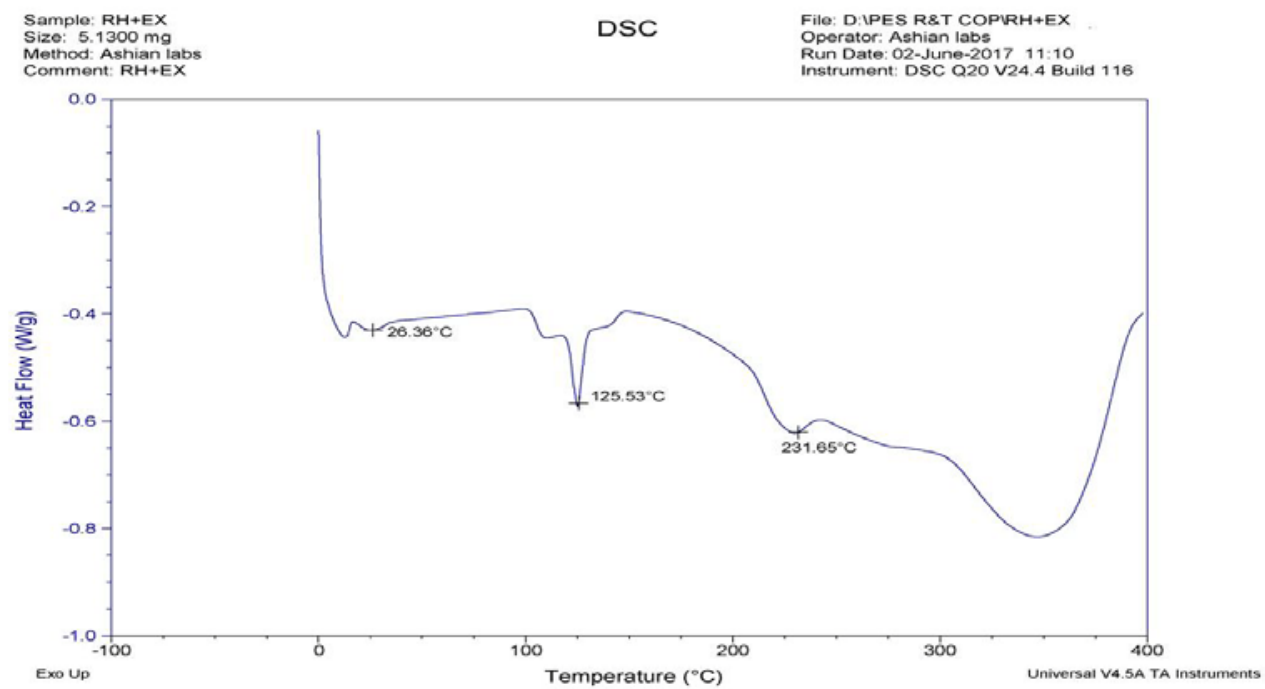

Fig. 2: DSC Spectra of ramosetron hydrochloride and excipients

\section{Evaluation of films}

All the prepared films were found to have good clarity, uniformity, were easily peelable and nonsticky. The scanning electron microscopy of the film (fig. 3) revealed that the films were smooth and clear with the uniform distribution of the drug. The films were found to weigh between $43.33 \mathrm{mg}$ and $80.00 \mathrm{mg}$ having thickness between $0.096 \mathrm{~mm}$ and $0.136 \mathrm{~mm}$. The folding endurance was found to be in the range of 745.33 to 946.33 . Increase in concentration of HPMC E15 and honey increased the folding endurance of the mouth dissolving films. The $\mathrm{pH}$ of all the films was found to be between 6.66-6.79 which is close to neutral $\mathrm{pH}$ and rules out any chances of 
irritation of oral mucosa. The percent elongation of all the films was found to be between $1.66 \%$ and $9.83 \%$. The assay values of all the films were found to be in the range of $98.05 \%$ and $102.17 \%$. The drug release profile of the films is as shown in fig. 4.

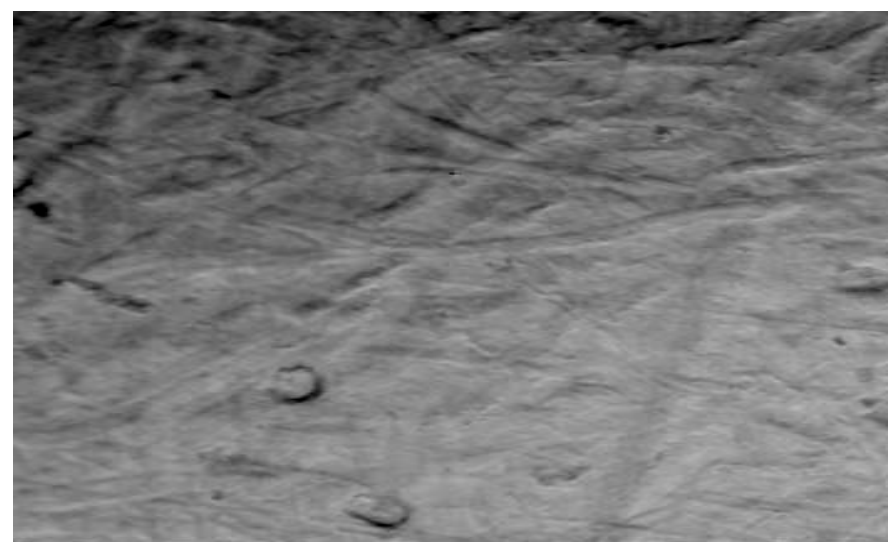

Fig. 3: SEM of ramosetron hydrochloride mouth dissolving the film

Table 3: Physicochemical characterization of the mouth dissolving film

\begin{tabular}{llllll}
\hline Code & Weight (mg) $^{\mathbf{a}}$ & Thickness (mm) $^{\mathbf{a}}$ & Folding endurance $^{\mathbf{a}}$ & pH $^{\mathbf{a}}$ & \% Elongation $^{\mathbf{a}}$ \\
\hline R1 & $43.33 \pm 2.08$ & $0.096 \pm 0.005$ & $745.33 \pm 3.51$ & $6.66 \pm 0.01$ & $1.66 \pm 0.72$ \\
R2 & $54.0 \pm 3.60$ & $0.10 \pm 0.01$ & $753.33 \pm 3.05$ & $6.70 \pm 0.01$ & $2.91 \pm 0.72$ \\
R3 & $75.0 \pm 2.64$ & $0.113 \pm 0.005$ & $806.33 \pm 3.05$ & $6.70 \pm 0.01$ & $3.33 \pm 0.72$ \\
R4 & $58.33 \pm 4.08$ & $0.113 \pm 0.005$ & $814.0 \pm 3.60$ & $6.75 \pm 0.01$ & $4.16 \pm 0.72$ \\
R5 & $63.33 \pm 2.08$ & $0.110 \pm 0.01$ & $822.66 \pm 2.51$ & $6.78 \pm 0.01$ & $6.25 \pm 0.0$ \\
R6 & $73.0 \pm 1.0$ & $0.123 \pm 0.0005$ & $839 \pm 3.60$ & $6.76 \pm 0.01$ & $7.75 \pm 0.43$ \\
R7 & $71.0 \pm 3.60$ & $0.133 \pm 0.005$ & $867 \pm 3.00$ & $6.77 \pm 0.01$ & $6.0 \pm 0.90$ \\
R8 & $72.33 \pm 2.51$ & $0.126 \pm 0.005$ & $879 \pm 3.60$ & $6.79 \pm 0.01$ & $8.0 \pm 0.43$ \\
R9 & $80.0 \pm 1.0$ & $0.136 \pm 0.005$ & $946.33 \pm 2.51$ & $6.73 \pm 0.02$ & $9.83 \pm 1.50$ \\
\hline
\end{tabular}

amean \pm SD $n=3$

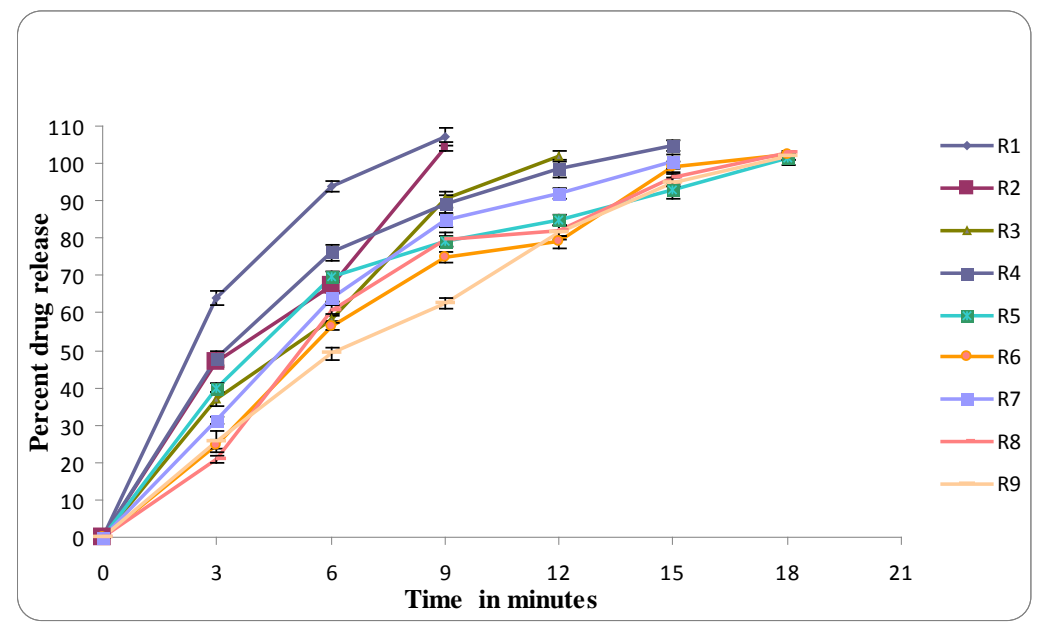

Fig. 4: Percent drug release profile of all mouth dissolving film formulation (mean $\pm S D n=3$ )

\section{Statistical analysis}

The design expert software 11.0 trial version helps to determine the model that best suits for the correlation between dependent variables and independent variables. The best-suited model was selected on the basis of parameters of regression analysis namely $\mathrm{p}$ value, adjusted and predicted $\mathrm{R}^{2}$ value [10]. ANOVA is implemented at $5 \%$ level of significance.

\section{Effect of formulation variables on disintegration time}

The $3^{2}$ factorial design on screening the data depicted a linear model as a best fit for response Y1 i. e disintegration time having $\mathrm{p}$ value $<0.0001$, adjusted $R^{2}$ of 0.9574 and predicted $R^{2}$ of 0.9224 (table 4). The adequate precision which measures signal to noise ratio was found to be 25.950. A ratio greater than 4 is desired.

The polynomial equation generated by the software is as given below:

$$
\mathrm{Y} 1=+81.14+9 \mathrm{X} 1+16.16 \mathrm{X} 2
$$

$\mathrm{X} 1$ and X2 were found to be significant factors having agonistic effect on the disintegration time and the same has been demonstrated in the response surface plot fig. 5, which shows an increase in the concentration of HPMC E15 and honey, increases the disintegration time of the film. X2 has a greater influence on disintegration time as seen from the coefficient value (16.16) than X1 (9.0). 


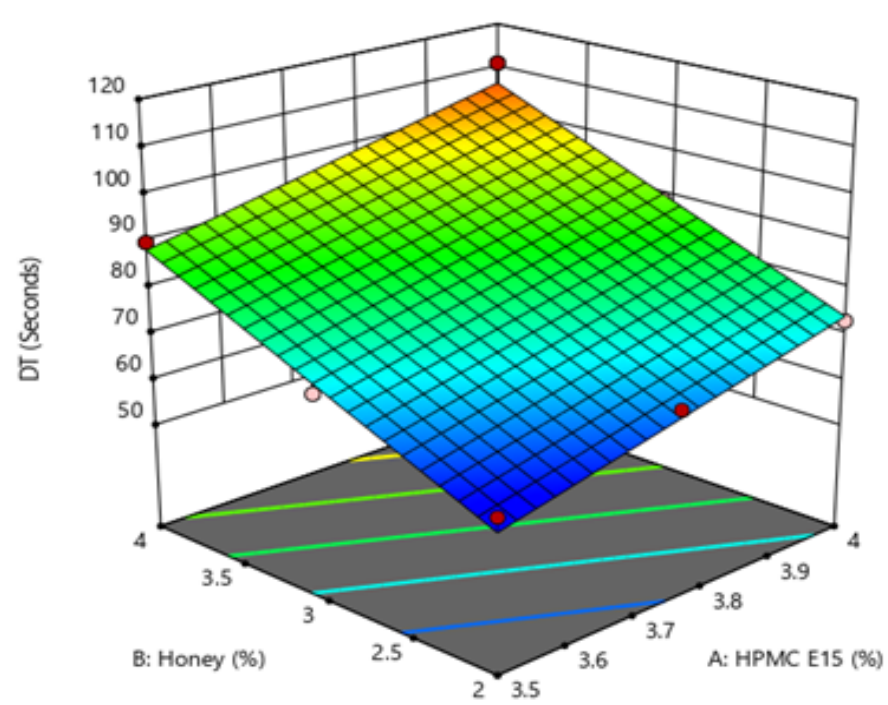

Fig. 5: Response surface plot for disintegration time

\section{Effect of formulation variables on tensile strength}

The analysis of response 2 shows a linear model as a best-fit model (table 4). The p-value was found to be $<0.0001$ hence the model was found to be significant, while the adjusted $R^{2}$ of 0.9574 and predicted $\mathrm{R}^{2}$ of 0.9224 were found to be in reasonable agreement with each other that is the difference was less than 0.2 . The adequate precision was found to be 93.419. The polynomial equation generated by the software for response $\mathrm{Y} 2$ is as given below:
Tensile strength in $\mathrm{kg} / \mathrm{cm}^{2}=+93.72+8.00 \mathrm{X} 1+10.70 \mathrm{X} 2$

From the equation, it can be predicted that $\mathrm{X} 2$ has the greater influence on tensile strength as seen from the beta coefficient value of 10.70 than the value of 8.0 coefficient value for X1. The response surface plot revealing the influence of independent variables, honey and HPMC E15 is depicted in fig. 6. Increase in concentration of honey made the film more robust and stiff than the use of just mere HPMC E15 polymer.

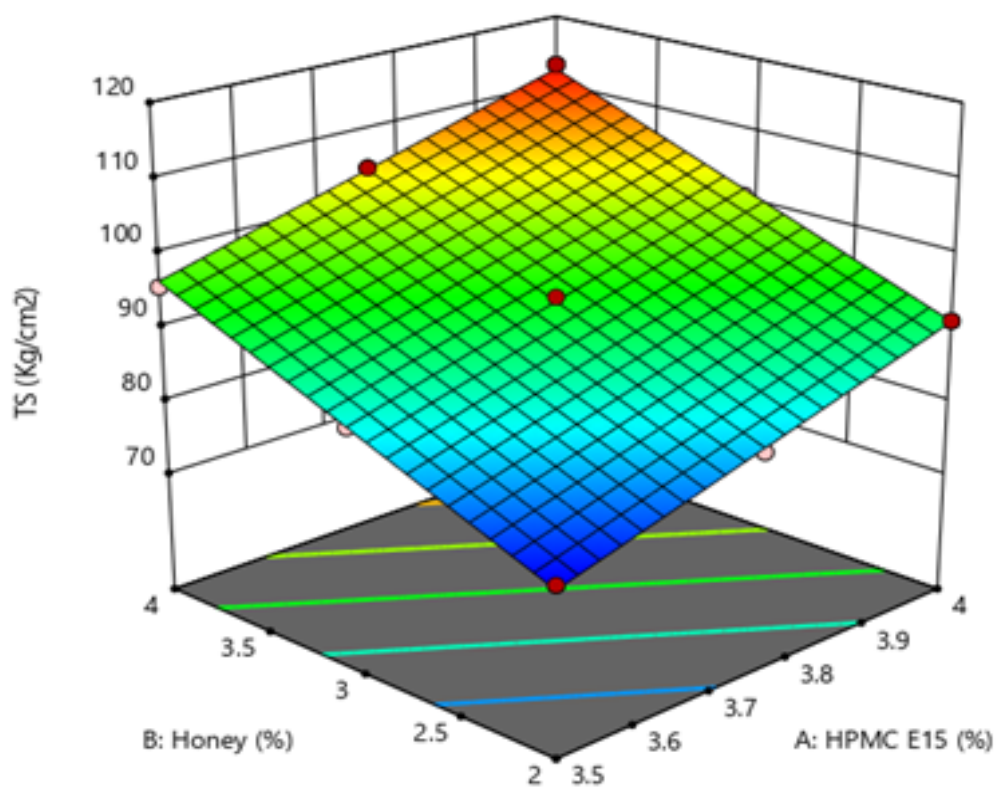

Fig 6: Response surface plot for tensile strength

\section{Effect of formulation variables on drug release}

Response 3 (Y3) analysis also shows the linear model as a best-fit model (table 4) with a p-value of 0.00013 , the adjusted $\mathrm{R}^{2}$ of 0.8550 and predicted $\mathrm{R}^{2}$ of 0.8013 . The adequate precision was found to be 13.828. The polynomial equation for $\mathrm{Y} 3$ is as given below:

Drug release at $9 \min (\mathrm{Y} 3)=+85.79-8.90 \mathrm{X} 1-12.52 \mathrm{X} 2$
From the equation, it can be interpreted that formulation variables X1 and X2 have an antagonistic influence on the drug release at $9 \mathrm{~min}$ from the mouth dissolving films as the coefficient estimate of $\mathrm{X} 1$ and $\mathrm{X} 2$ have negative values of- 8.90 and-12.52 respectively. The increase in the concentration of HPMCE15 and Honey decreases the release of the drug from the mouth dissolving as depicted in fig. 7. 


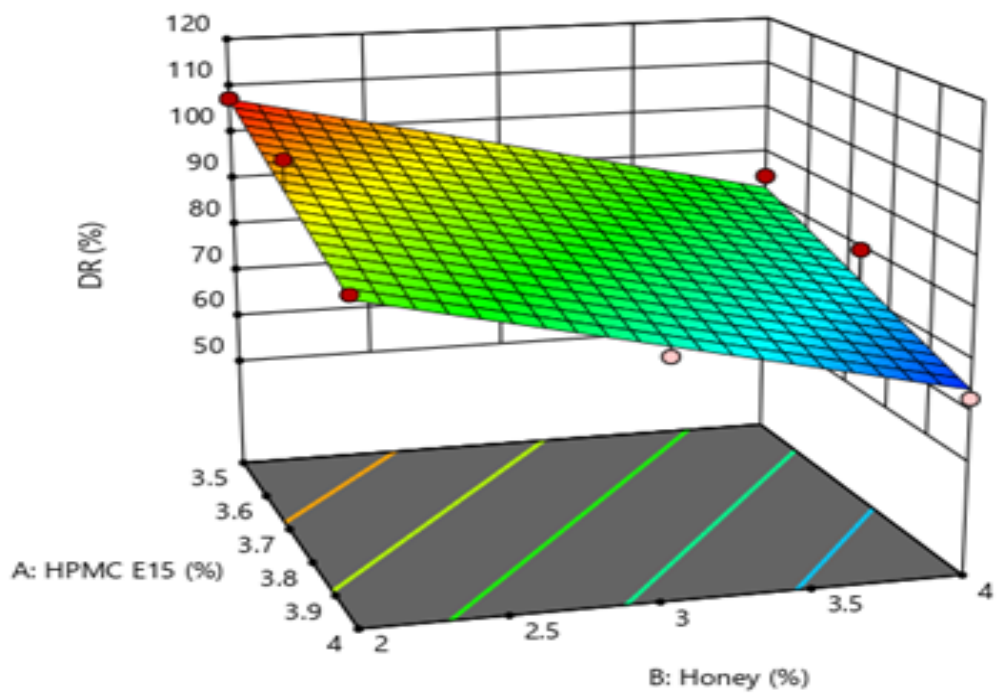

Fig. 7: Response surface plot for drug release

Table 4: Fit summary of the highest order polynomial of responses

\begin{tabular}{llllll}
\hline Response/ & Y1 & & Y2 & Y3 \\
\hline Source & f value & p Value & f value & p value & f value \\
\hline Linear vs Mean & 91.00 & $<0.0001$ & 1113.70 & $<0.0001$ & 24.59 \\
2FI vs Linear & 1.10 & 0.3428 & 2.46 & 0.1778 & 0.0013 \\
Quadratic vs 2FI & 4.12 & 0.1377 & 0.0784 & 0.9264 & 4.06 \\
\hline
\end{tabular}

\section{Statistical optimization}

Optimization of the ramosetron hydrochloride mouth dissolving film was done using the design expert software 11.0 trial version by setting the desired goals for the responses. The goals set for the present study was to have minimum disintegration time and maximum drug release at $9 \mathrm{~min}$. The software provided four solutions based on the goals. One of the solutions provided by the software was among the formulation batches ie R1. Formulation R1 was chosen as the best-optimized formulation having desirability of 0.9999 that would give a mouth dissolving film of ramosetron hydrochloride having predicted disintegration time of 55.98 seconds, the tensile strength of $75.02 \mathrm{Kg} / \mathrm{cm}^{2}$ and that would release $107.21 \%$ drug at the end of $9 \mathrm{~min}$. The optimized formulation showed the responses close to that predicted by the software. The actual responses of the optimized batch were found to have a disintegration time of 57.0 seconds, tensile strength of $75.02 \mathrm{Kg} / \mathrm{cm}^{2}$ and that would release $104.21 \%$ drug at the end of $9 \mathrm{~min}$.

\section{Stability study}

The stability studies done on the optimised batch were found to be within the specification. The films were clear, non-tacky having folding endurance of 730.00, disintegration time of 57 seconds and releasing $104.21 \%$ drug completely at the end of $9 \mathrm{~min}$.

\section{CONCLUSION}

The mouth dissolving film of ramosetron hydrochloride that would provide ease of administration to cancer patients of any age group was successfully developed. Design of experiment was found to be a useful tool in understanding the influence of excipients on the performance of the film. The formulation batches were successfully optimized using design expert software. The formulation R1 was found to be the best-optimized batch with disintegration time of 57 seconds and drug release of $104.21 \%$ drug at the end of $9 \mathrm{~min}$.

\section{ACKNOWLEDGMENT}

I would like to thank Dr S. N. Mamle Desai, Principal of P. E. S's Rajaram and Tarabai Bandekar College of Pharmacy for providing research facility and for his support whenever required and my guide Dr H. M Tank for his guidance and support.

\section{AUTHORS CONTRIBUTIONS}

Miss Suwarna S Bobde is the author for this publication. She is a Research Scholar at School of Pharmacy, R K University, Rajkot Gujarat, and is currently working as Assistant Professor in Department of Pharmaceutics at P. E. S's Rajaram and Tarabai Bandekar College of Pharmacy Farmagudi-Ponda Goa, where she has carried out all the research work under the guidance of Dr H M Tank; Principal, Atmiya Institute of Pharmacy Rajkot, Gujarat.

\section{CONFLICTS OF INTERESTS}

All the authors have none to declare

\section{REFERENCES}

1. Gordon P, LeGrand SB, Walsh D. Nausea and vomiting in advanced cancer. Eur J Pharmacol 2014;722:187-91.

2. Rowbottom L, McDonald R, Turner A, Chow E, DeAngelis C. An overview of radiation-induced nausea and vomiting. J Med Imaging Radiation Sci 2016;47:S29-S38.

3. Zaidan M, Soufi L, Hafeez M, Abdelwahid M, Rasul KI. Assessing prescribing patterns for the prevention of chemotherapyinduced nausea and vomiting in national centre for cancer care and research. Saudi Pharma J 2015;23:381-7.

4. Navari RM. Managing nausea and vomiting in patients with cancer: what works. Oncol J 2018;32:121-5.

5. Sanmukhani JJ, Pawar P, Mittal R. Ramosetron hydrochloride for the prevention of cancer chemotherapy-induced nausea and vomiting: the indian experience. South Asian J Cancer 2014;3:132-7.

6. Choudhary DR, Patel VA, Chhalotiya UK, Patel HV, Kundawala AJ. Natural polysaccharides as film former: a feasibility study for development of rapid dissolving films of ondansetron hydrochloride. Int J Pharm Pharm Sci 2012;4 Suppl 3:78-85.

7. Induru J. Preliminary screening and development of formulation design space for buccal thin films of isradipine. Int J Pharm Pharm Sci 2012;4:179-84.

8. Iriventi P, Gupta VN. Oral dissolving films of celecoxib inclusion complexes using musa paradisiacal as a super disintegrant in the treatment of psoriatic arthritis. J Pharm Res 2017;11:517-21. 
9. Dinge A, Nagarsenker M. Formulation and evaluation of fast dissolving films for delivery of triclosan to the oral cavity. AAPS PharmSciTech 2000;9:349-56.
10. Bhattacharya S, Prajapati BG. Formulation and optimization of celecoxib nanoemulgel. Asian J Pharm Clin Res 2017;10:35365. 